\title{
The Equilibrium Design of Radial Magnetic Force for Reduction of Vibration in IPM type BLDC Motor
}

\author{
Gyeong-Deuk Lee* and Gyu-Tak Kim ${ }^{\dagger}$
}

\begin{abstract}
In this paper, influence of vibration on cogging torque and Radial Magnetic Force(RMF) imbalance was investigated in the IPM type BLDC motor. Design of cogging torque reduction and the RMF equilibrium was proceed applied to Design of Experiment(DOE). Vibration test results, the RMF imbalance was confirmed that a significant impact of vibration.
\end{abstract}

Keywords: BLDC Motor, Vibration reduction, Cogging torque, Radial magnetic force, Natural frequency

\section{Introduction}

Interior Permanent Magnet Synchronous Motor(IPMSM) has permanent magnets embedded in the robust rotor core. So a reluctance torque is generated by the difference in $\mathrm{d}$-axis, q-axis inductance, and the torque of IPMSM is greater than Surface Permanent Magnet Synchronous Motor (SPMSM). But local flux saturation is generated due to inserting permanent magnet into the rotor and the large magnetic flux density at small effective air-gap makes a loud noise and the vibration occurs when the motor is operating [1-3]. Vibration causes of the motor are cogging torque and RMF imbalance action on the motor stator or rotor.

Especially, the resonance was produced in case of the frequency of torque in the same band with the natural frequency. The resonance degraded the performance of motor and adversely affected other systems [4-6].

In this paper, the cogging torque and RMF were the causes of electromagnetic vibration. So, the notch was installed for the reduction of cogging torque. Meanwhile, the RMF equilibrium model was designed by changing radius of rotor and installed notch in order to reduce vibration caused by RMF imbalance. Permanent magnets were arranged by dividing in order to compensate for decrease of the magnetic flux density according to air gap increment with variation of rotor radius.

The RMF imbalance could have a larger impact on vibration during BLDC driving mode IPM motor than cogging torque. So, the equilibrium of RMF is an efficient method of vibration reduction better than reduction of cogging torque.

$\dagger$ Corresponding Author: Dept. of Electrical Engineering, Chanwon National University, Korea. (gtkim@cwnu.ac.kr)

* Dept. of Electrical Engineering, Changwon National University, Korea. (kd_lee@cwnu.ac.kr)

Received: January 7, 2015; Accepted: October 17, 2015

\section{Optimal Design to Model}

\subsection{Design models and specifications}

The specifications of basic model are shown in Table 1. The basic model core shapes are shown in Fig. 1.

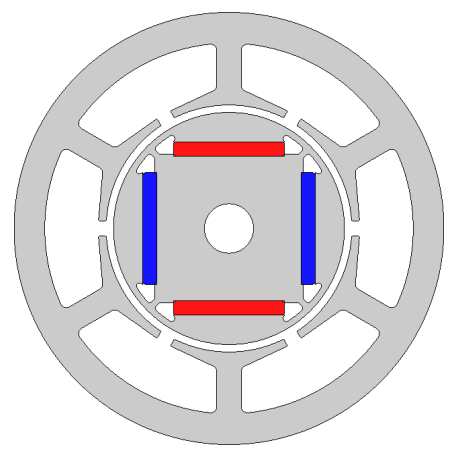

Fig. 1. The shape of basic model

Table 1 The specification of basic model

\begin{tabular}{c|c}
\hline Item & Specification \\
\hline Rated speed $(\mathrm{RPM})$ & 3200 \\
\hline Rated torque $(\mathrm{N} \cdot \mathrm{M})$ & 0.4 \\
\hline Pole/Slot & $4 / 6$ \\
\hline Air-gap length $(\mathrm{mm})$ & 1.2 \\
\hline Winding type & 1.02 \\
\hline Br $(\mathrm{T})$ & 41 \\
\hline Stack length $(\mathrm{mm})$ & 70
\end{tabular}

\subsection{Design of notch}

The position and width of a notch, which can offset the cogging torque can be calculated with the energy distribution of the air-gap using a Fourier series $[7,8]$. The position function of notch derives formula from assuming infinite energy of slot. So the energy distribution of actual notch was varied. Consequently, the notch size was chosen 


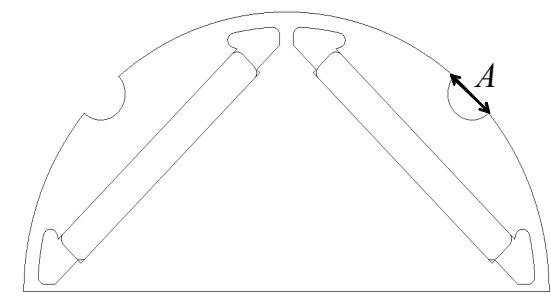

(a) The notch

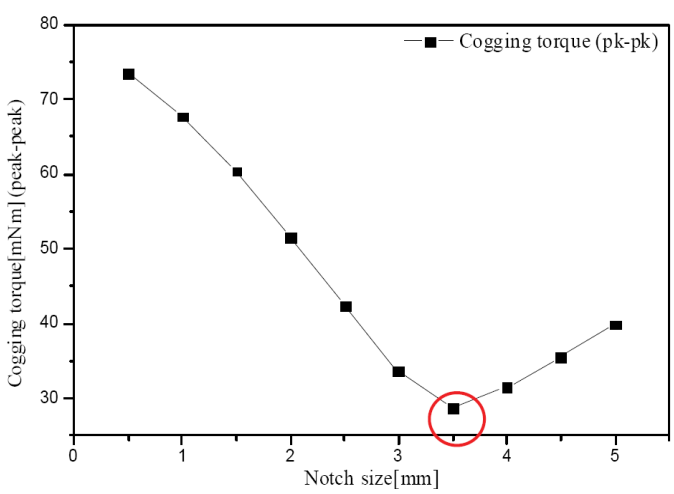

(b) The notch width - the cogging torque

Fig. 2. The cogging torque according to the rotor notch width

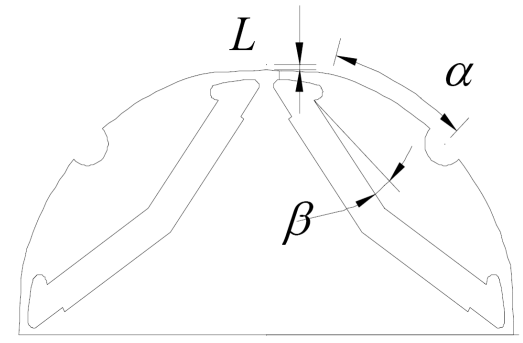

Fig. 3. The Parameters for the design of RMF equilibrium

using (Design of Experiments)DOE and (Finite Element Method)FEM.

Fig. 2 (a) shows the shape of the rotor core installed notch and the diameter $\mathrm{A}$ of the design variables was selected rotor shape when the cogging torque is minimum. Fig. 2 (b) shows the cogging torque variation conditions according to the change of notch width.

\subsection{Shape optimization}

The unbalanced RMF refers to a vibration source that the axis ratio of RMF is closing to zero. The RMF axis ratio is the ratio of the major and minor axis. The more the RMF axial ratio is closer to 1 , the more the RMF is balanced.

Fig. 3 shows the rotor parameters for the design of equilibrated RMF. The design of RMF equilibrium was performed at the rotor of minimized cogging torque model.
The design was proceed by DOE. At this time, the design parameters are $\alpha, \beta$ and $L . \alpha$ is the angle of beginning to decrease the radius of the rotor from the d-axis, $\beta$ is slope of the permanent magnet. And $L$ is the reduced length of the rotor diameter. The more $\alpha$ was larger, the more RMF was equilibrated. Especially, 0.878 of RMF axial ratio, it was achieved to 2.51 times RMF equilibrium from $\alpha=30^{\circ}$, $L=0.4(\mathrm{~mm})$ compared to basic model.

As a result of equilibrium RMF design, RMF equilibrium became maximum from $\beta=10^{\circ}$. In this case, 0.888 of the axial ratio compared to the basic model was achieved to 2.54 times equilibrium. The RMF changes according to the design parameters shown in Table 2 and 3 .

Table 2. The RMF axial ratio according to $\alpha$ and $L$

\begin{tabular}{c|c|c|c|c|c}
\hline$L$ & 0 & 7.5 & 15 & 25 & 30 \\
\hline 0.1 & 0.689 & 0.702 & 0.695 & 0.700 & 0.649 \\
\hline 0.2 & 0.660 & 0.656 & 0.656 & 0.694 & 0.792 \\
\hline 0.3 & 0.674 & 0.670 & 0.673 & 0.689 & 0.835 \\
\hline 0.4 & 0.688 & 0.683 & 0.691 & 0.682 & 0.878 \\
\hline 0.5 & 0.694 & 0.695 & 0.708 & 0.694 & 0.801 \\
\hline
\end{tabular}

Table 3 The RMF axial ratio according to $\beta$

\begin{tabular}{c|c|c|c|c|c}
\hline$\beta$ & 2 & 4 & 6 & 8 & 10 \\
\hline RMF ratio & 0.878 & 0.876 & 0.879 & 0.880 & 0.888 \\
\hline
\end{tabular}

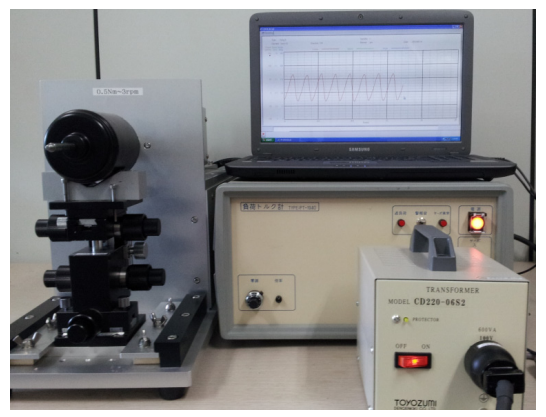

Fig. 4. Cogging torque tester

Fig. 4 shows the cogging torque measurement equipment. It was used by Protec corp, PT-1940.

The cogging torque experimental values of each model were compared to calculation values in Fig. 5.

The cogging torque of minimized cogging torque model compared with the cogging torque of basic model was reduced by $62 \%$, the cogging torque of RMF equilibrium model compared with the cogging torque of basic model was increased by $77 \%$. The experimental values measured $21(\mathrm{mN} \cdot \mathrm{m})$ largely than calculation values. This is thought to be caused by the friction according to bearings etc.

\section{Analysis of RMF}

As shown in Fig. 6, for electro-magnetic machines, the 


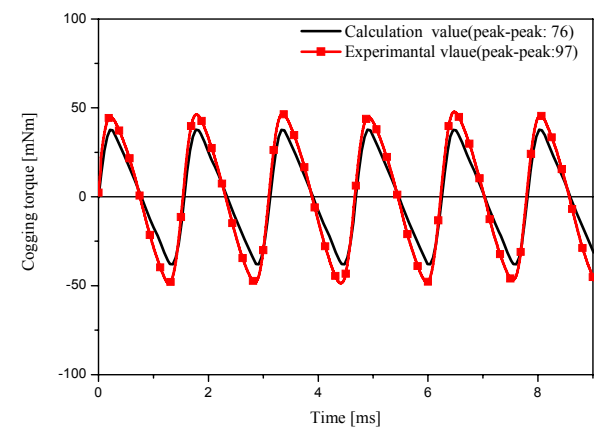

(a) The basic model

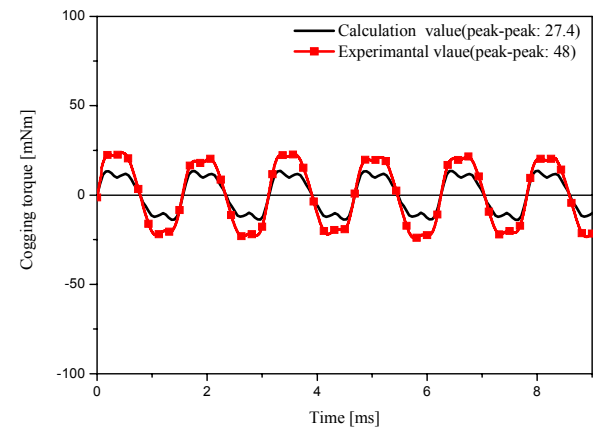

(b) The minimized cogging torque model

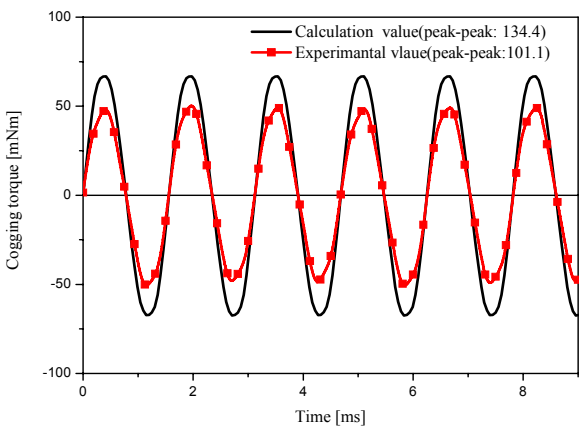

(c) The RMF equilibrium model

Fig. 5. The cogging torque

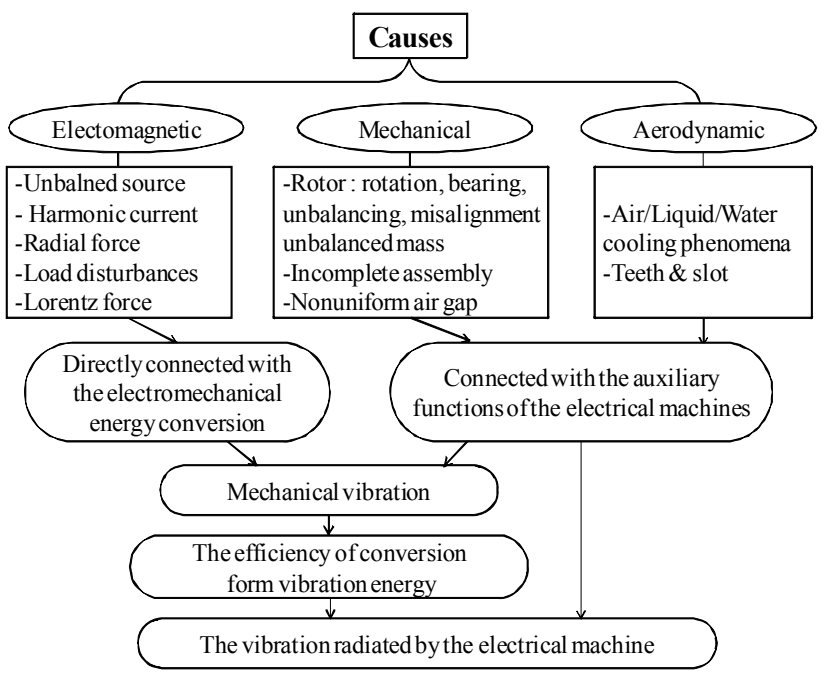

Fig. 6. Origins of noise and vibration and transfer process

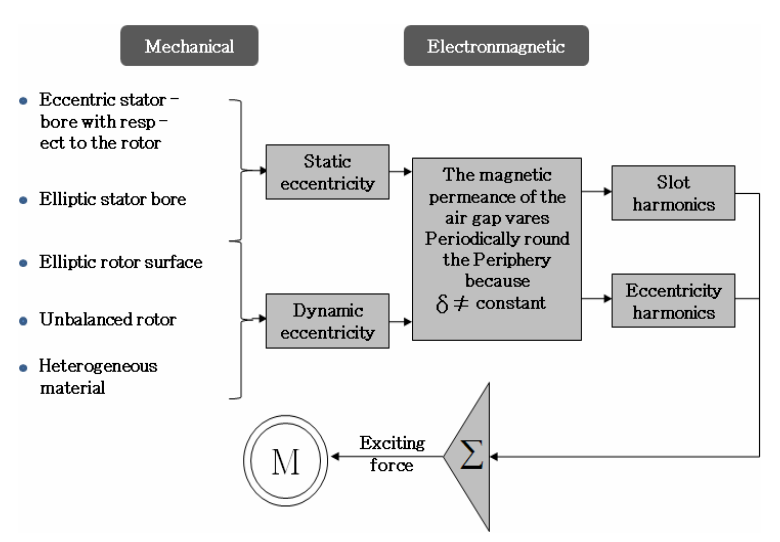

Fig. 7. RMF by unbalance of air-gap

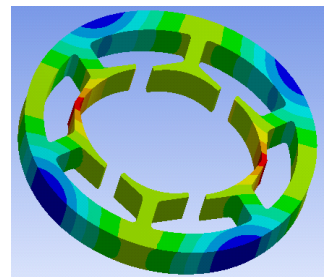

(a) 1 st mode $(2402(\mathrm{~Hz}))$

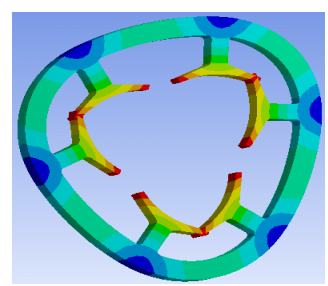

(c) 3rd mode $(5599(\mathrm{~Hz}))$

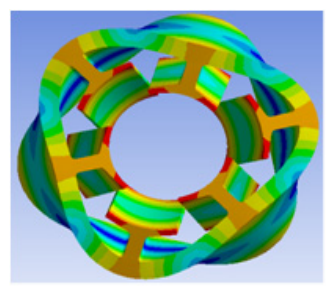

(e) 5 th mode $(8811(\mathrm{~Hz}))$

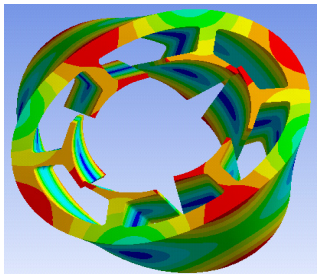

(b) 2nd mode (4293 (Hz))

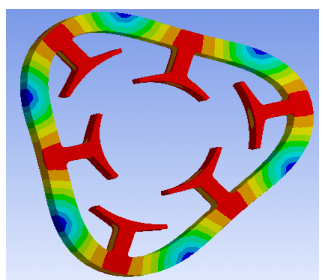

(d) 4 th mode $(6710(\mathrm{~Hz}))$

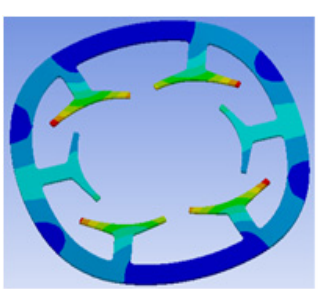

(f) 6th mode $(9333(\mathrm{~Hz}))$
Fig. 8. Mode shape about natural frequency

causes of noise can come from several factors: an electromagnetic factor, a mechanical factor, and an aerodynamic factor.

Fig. 7 shows the effects of the RMF on the air-gap unbalance due to mechanical factors of various kinds. The RMF was generated by a combination of electro-magnetic and mechanical phenomena [9].

\subsection{Analysis of natural frequency}

Mode represents unique dynamic aspects, when stator was vibrated by RMF with any frequency, the behavior of 
the stator appears through unique mode aspects in frequency band of RMF [10].

The natural frequency of stator takes a dominant role in vibration and resonance, Modal analysis was performed. Material of the stator is silicon steel(S23-50PN800), and mass density is $7850\left(\mathrm{Kg} / \mathrm{m}^{3}\right)$. Poisson ratio is 0.24 and Young's modulus is $200(\mathrm{Gpa})$.

Fig. 8 shows the modal analysis results. It is mode shape about natural frequency of the stator and each natural frequency which shows frequency of each modes of analytical model. Fig. 8 (a) and (b) in each 2402(Hz) and $4293(\mathrm{~Hz})$ is elliptical workout mode. Compared to other frequency modes it is main mode that generate large vibration and noise, therefore it should be avoided resonance in elliptical workout mode such as (a) and (b).

\subsection{Calculation of RMF}

Natural frequency analysis did not consider effect of rotor. So it is hard to compare to vibration effect according to rotor shape change. Therefore, in order to analyze basic model and improved model vibration caused by changing in air-gap magnetic flux were compared with aspect and distribution of RMF.

Electromagnetic vibration source was caused by mechanical factors and electromagnetic phenomena of mutual organic relationship. If frequency of electromagnetic RMF is similar area to natural frequency of motor structure, it causes resonance. Wear of parts and motor driving performance debase, influence other system.

The source of electromagnetic vibration and noise is generated by radial force density of stator's surface from air-gap magnetic field. The radial force density can be calculated by Maxwell's stress tensor method as (1)[11].

$$
F_{\text {rad }}\left(\theta_{s}, t\right)=\frac{1}{2 \mu_{0}}\left[B_{r}^{2}\left(\theta_{s}, t\right)-B_{\theta}^{2}\left(\theta_{s}, t\right)\right]
$$

Here, $F_{r a d}$ is the radial component of force density, $B_{r}$ and $B_{\theta}$ are radial and tangential components of the air-gap flux density, $\mu_{0}$ is permeability of free space, $\theta_{s}$ is the angular position and $t$ is the time.

Fig. 9 is result that compare distribution pattern of RMF. The more RMF pattern was similar to the circle, the more was balanced. Compared to the basic model, minimized cogging torque model was increased in size of minor axis

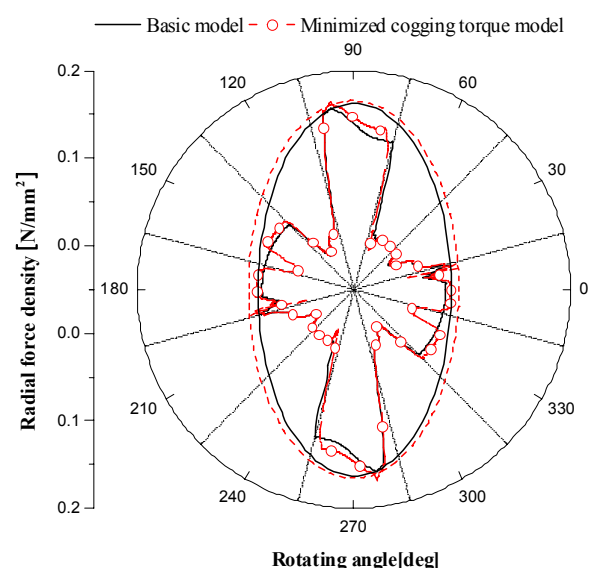

(a) Minimized cogging torque model

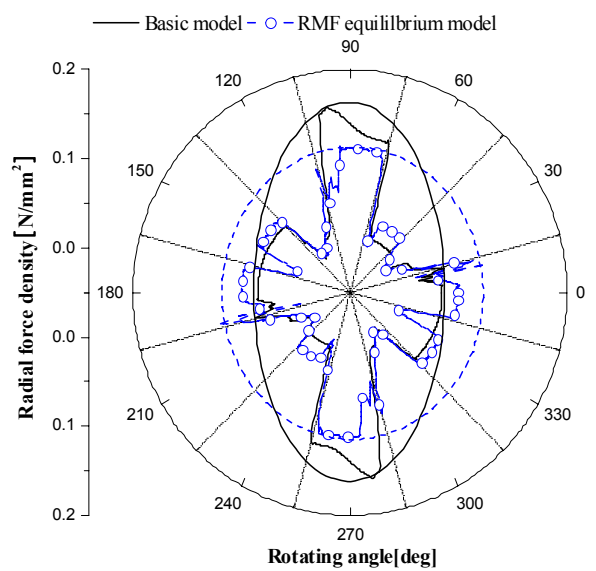

(b) RMF equilibrium model

Fig. 9. RMF distribution

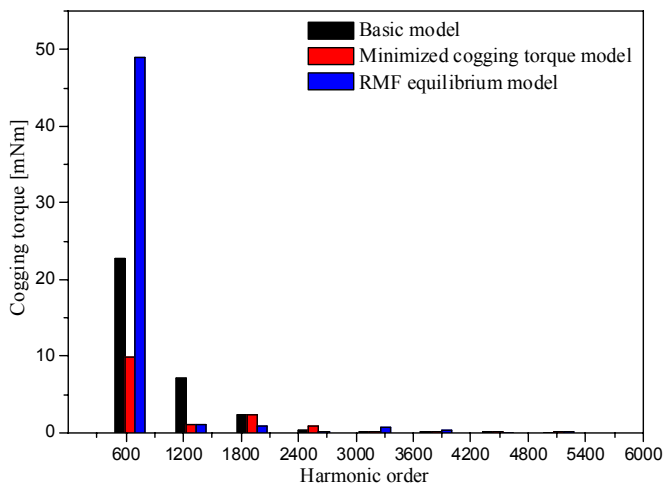

(a) Harmonic analysis of cogging torque

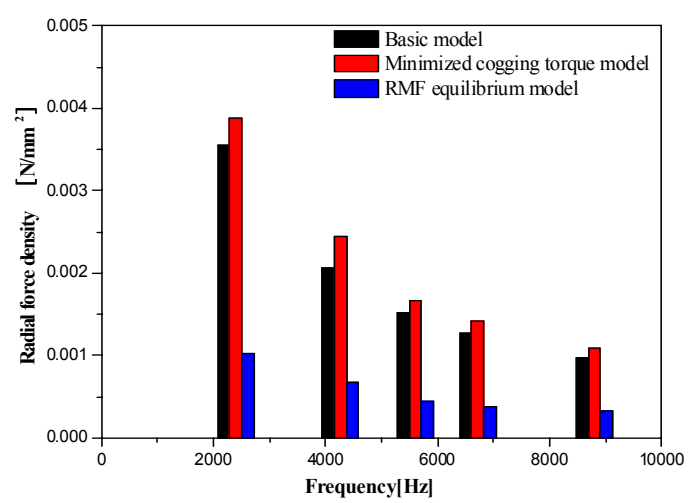

(b) Harmonic analysis of RMF

Fig. 10. Harmonic analysis of natural frequency band 
and major axis. RMF equilibrium model was shown result that decrease of minor axis and increase of major axis. Calculating proportion of minor axis and major axis, minimized torque model was balanced more than basic model that proportion of axis is 0.43 from 0.35 . Proportion of axis of RMF equilibrium model is 0.888 , more than basic model was 2.5 times balanced.

Fig. 10 (a) is harmonic analysis of cogging torque and (b) is result of harmonic analysis in natural vibration frequency band of RMF. Result of harmonic analysis of cogging torque, amplitude is small on elliptical motion mode in $2402(\mathrm{~Hz})$ and $4293(\mathrm{~Hz})$. Therefore it is considered that vibration according to cogging torque is not big. But harmonic component of RMF was overlapped in unique vibration mode 1 and 2 . Accordingly, it is considered that according to RMF occurred big vibration.

\section{Vibration Test}

Fig. 11 shows vibration test equipments. The acceleration sensor was used by the PV-97C model. A signal analyzer was used for SA-01A-4 model. Vibration signal was amplified to use UV-06A amplifier. Vibration signals of shock by electromagnetic absorbing force were measured in the direction of radiation.
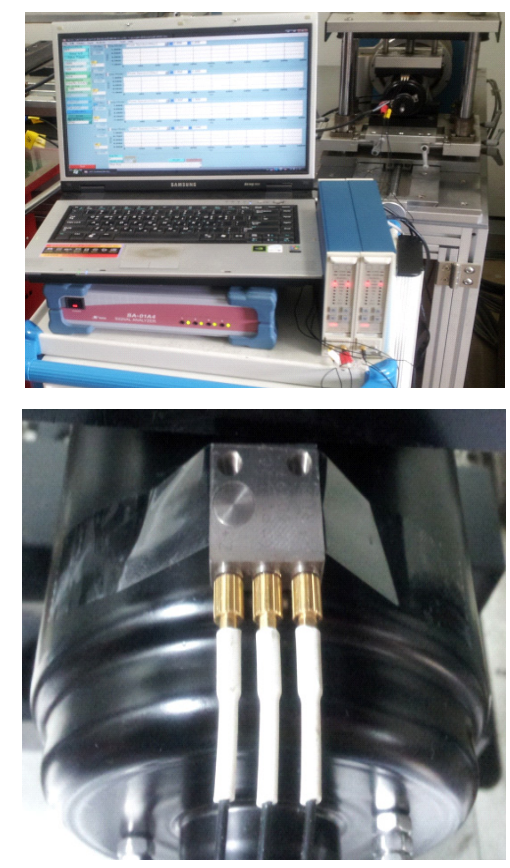

Fig. 11. Experimental equipment and acceleration sensor

Fig. 12 (a) shows the vibration test results of the basic model and the minimized cogging torque model. (b) shows the vibration test results of the basic model and the RMF equilibrium model. And (c) shows the vibration test results of the minimized cogging torque model and the RMF

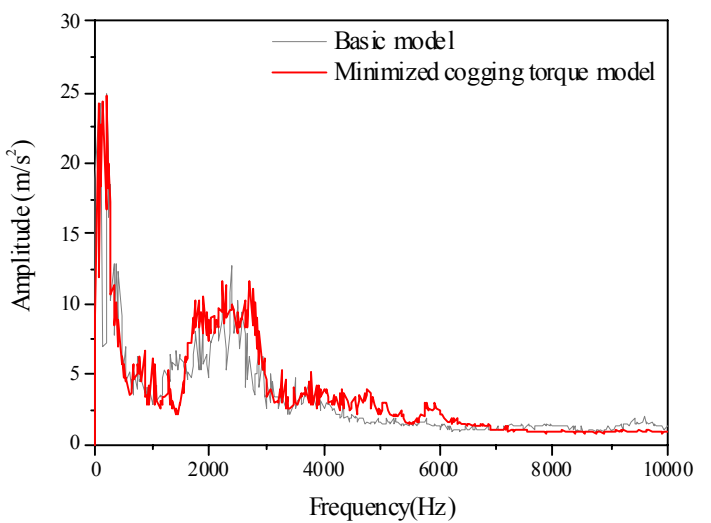

(a) Comparison of the basic model and the minimized cogging torque model

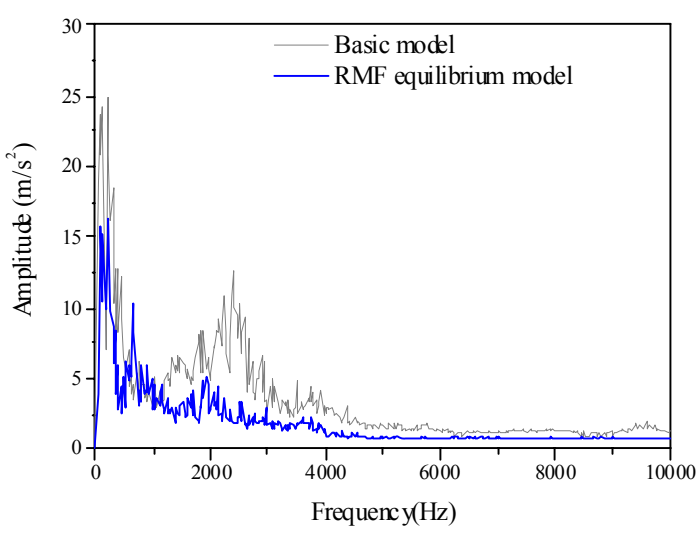

(b) Comparison of the basic model and the RMF equilibrium model

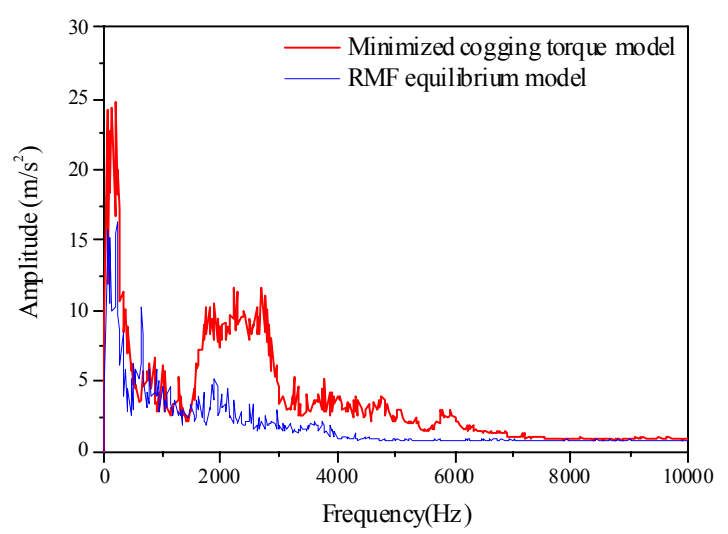

(c) Comparison of the minimized cogging torque and the RMF equilibrium model

Fig. 12. Vibration test result

equilibrium model.

As results, it can be seen that the size of the vibration of the minimized cogging torque model was increased than the basic model, the size of the vibration of the RMF equilibrium model was greatly reduced than the basic model.

It can be seen that the RMF imbalance has a significant impact on the vibration than the cogging torque. 


\section{Conclusion}

In this paper, the influence of the RMF imbalance and cogging torque on the vibration were compared and analyzed in IPM type BLDC motor.

The minimized cogging torque model and the RMF equilibrium model were designed by using the FEM and DOE. The cogging torque of the minimized cogging torque model was $62 \%$ reduction compared to the basic model. But RMF corresponding to the 1st mode of vibration was increased 1.1 times compared to the basic model. Rather, the vibration was increased.

Meanwhile, the cogging torque of the RMF equilibrium model was increased 1.77 times compared to the basic model. But RMF was $70 \%$ reduction compared to the basic model. So, the vibration was reduced.

In other words, it was confirmed that RMF imbalance is affecting significantly the vibration than cogging torque in IPM type BLDC drive motor.

\section{Acknowledgements}

This work was supported by the Human Resource Training Program for Regional Innovation and Creativity through the Ministry of Education and National Research Foundation of Korea (2015H1C1A1035824)

\section{References}

[1] Gyu-Hong Kang, Young-Dae Song, Gyu-Tak Kim and Jin-Hur, "A Novel Cogging Torque Reduction Method for Interior Type Permanent Magnet Motor", IEEE Transaction on. Industry Applications, vol. 45, No. 1, pp. 161-167, 2009.

[2] J. P. Hong et al., "Analysis of radial force as a source of vibration in an induction motor with skewed slots," IEEE Transaction on. Magnetics, Vol. 33, No. 2, pp. 1650-1653, 1997.

[3] Jin-Hur, Byeong-Woo Kim, "Rotor Shape Design of an Interior PM Type BLDC Motor for Improving Mechanical Vibration and EMI Characteristics", Journal of Electrical Engineering \& Technology Vol. 5, No. 4, pp. 592-596, 2010,

[4] R. S. Colby, F. M. Mottier and T. J. E. Miller, "Vibration modes and acoustic noise in a four-phase switched reluctance motor," IEEE Transaction on. Industry Applications, Vol. 32, No. 6, pp. 1357-1363, 1996

[5] Jin Hur, Jin-Wook Reu, Byeong-woo Kim, Gyu-Hong Kang, "Vibration Reduction of IPM-Type BLDC Motor Using Negative Third Harmonic Elimination Method of Air-Gap Flux Density," IEEE Transactions on. Industry Applications, Vol. 47, No, 3, pp. 13001309, 2011.
[6] Won-Ho Kim, "A Stress Analysis Method for the Rotor Design of an IPMSM Considering Radial Force", Journal of Electrical Engineering \& Technology Vol. 9, No. 3, pp. 882-887, 2014

[7] M.-F. Hsieh, D. G. Dorrell, Y.-H. Yeh, and S. Ekram, "Cogging torque reduction in axial flux machines for small wind turbines," in Proc. 35th IEEE Annu. Conf. Ind. Elect. (IECON), pp. 4435-4439, 2009.

[8] Xiuhe Wang, Yubo Yang, Dajin Fu "Study of cogging torque in surface mounted permanent magnet motors with energy method," Journal of Magnetism and Magnetic Materials, Vol. 267, No. 1, pp. 80-85, 2003.

[9] D. G. Dorrell, W. T. Thomson and Steven Roach, "Analysis of air gap flux, current, and vibration signals as a function of the combination of static and dynamic airgap eccentricity in 3phase induction motor", IEEE Transaction on. Industry Applications, vol. 33, no. 1, pp. 24-34, 1997.

[10] Logan, Daryl L., "A First Course in the Finite Element Method", Thomson Learning, 2007.

[11] Jacek F. Gieras, Chong Wang, Joseph Cho Lai, "Noise of Poly phase Electrical Motors", Taylor \& Francis Group, 2006

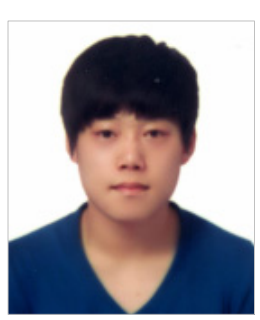

Gyeong-Deuk Lee He received B.S degree in electrical engineering from Changwon National university. His research interests are electrical machine and FEM analysis.

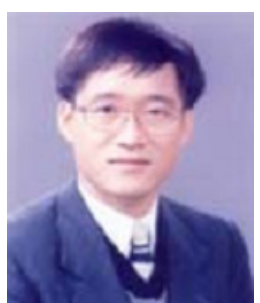

Gyu-Tak Kim He received B.S, M.S and Ph.D degree in electrical engineering from Hanyang University, Korea. $\mathrm{He}$ is presently a Professor of Changwon National University. His research interests are electrical machine and FEM analysis. 